\title{
The Research on Wind Resistance Performance Of Traditional Houses in Southern Fujian
}

\author{
Huang Zhuangwei \\ School of Civil Engineering and Architecture \\ Xiamen University of Technology,Xiamen,China \\ 21129011@qq.com
}

\begin{abstract}
Keywords: traditional houses in southern Fujian, wind resistance performance research Abstract: The traditional houses in southern Fujian Province is an important part of Chinese dwellings. They are located on both sides of the Taiwan Strait where the wind disasters happened frequently. In the long history, many considerations on wind resistance performance of traditional houses in southern Fujian are reflected in various aspects of building construction. The article will focus on these analysis and researches.
\end{abstract}

\section{Introduction}

'Minnan' region, including three cities of Quanzhou, Zhangzhou and Xiamen in southern Fujian and the counties under their jurisdiction, where belongs to the southern subtropical monsoon climate. The three cities of Quanzhou, Zhangzhou and Xiamen are neighboring geographically and has the same customs. The 'Minnan' dialect is used as the main language.In the history, Jinmen and most areas of Taiwan had close exchange in the population and economy. They all belong to the same cultural circle of 'Minnan' region. The buildings originate from the traditional houses in southern Fujian. They have the same spatial composition of traditional Chinese architecture and also have the regional features in terms of layout, appearance, modeling, and sculpture details.

In the history, typhoons occurred frequently in southern Fujian and Taiwan. Therefore, there are many considerations on wind resistance performance of traditional houses in southern Fujian in terms of layout, carpentry work and constructions. The article will be based on the analysis of the traditional houses in southern Fujian and study the adaptive construction methods for responding to typhoons.

\section{The history of typhoon and its destructive effect on architecture in southern Fujian}

Southern Fujian and Taiwan are between two sides of the Taiwan Strait. Due to the special geographical location and climatic conditions, they are often hit and affected by typhoon. When the typhoons land or impact, They not only have a large wind force, but also often bring heavy rainfall.the trigger storm surges along the coast and floods in the river that poses a great threat to people's lives, property and the development of economy and society. Taking Xiamen as an example, according to the statistics of Water Resources of Xiamen, during 58 years from 1949 to 2007, on average, strong typhoon disaster occurred every 1 to 6 years in Xiamen, causing serious property losses.

The destructive effect by typhoons on the traditional Chinese folk houses with civil structures is enormous. In the residential houses which are affected by typhoons, roof collapse, roof lifting, and wall damage occur generally. The wind also exerts strong pressure on weak parts such as windows and doors, leading to their destruction directly.

Therefore, how to resist and avoid wind is a problem that must be faced for the traditional folk houses in southern Fujian. The ancestors of southern Fujian accumulated a lot of experience in the 
past long history and developed a set of effective construction methods in terms of layout, shape and structural details.

\section{Wind shelter by the layout of houses}

The traditional houses in southern Fujian have the spatial commonality of the Chinese traditional architecture, that is the basic layout method, like axis symmetry and the courtyard in the center.Taking the typical dwellings in 'Da-cuo' ( big house) style in Quanzhou as an example, it is generally divided into 'San-jian-zhang' and 'Wu-jian-zhang' ( three rooms and five rooms, its standard width of a room in an old-style house about 10 chi and the length of a purlin ). According to the increase of courtyards, following the direction of depth is called 'Liang-luo-da-cuo' ( big houses with 'Xia-luo' and 'Ding-luo') and 'San-luo-da-cuo'( big houses with 'Xia-luo','Ding-luo' and 'Hou-luo'). That is to say, as a horizontal extension, there are always auxiliary facilities on both sides of the main building, known as 'Hu-cuo'. 'San-jian-zhang-liang-luo-da-cuo' can be considered as the basic unit of traditional house and it can increase the depth and width by adding new building. (Figure 1) Which slightly smaller than it is the triple-sides house like 'San-jian-zhang-Ju-tou-zhi' and 'Wu-jian-zhang-Ju-tou-zhi'. The so-called 'Ju-tou-zhi' is the house only build until the end of 'Ju-tou' (two rooms on the both sides of first courtyard) without 'Xia-luo' and at the gable of 'Ju-tou' build a wall facing the main street.

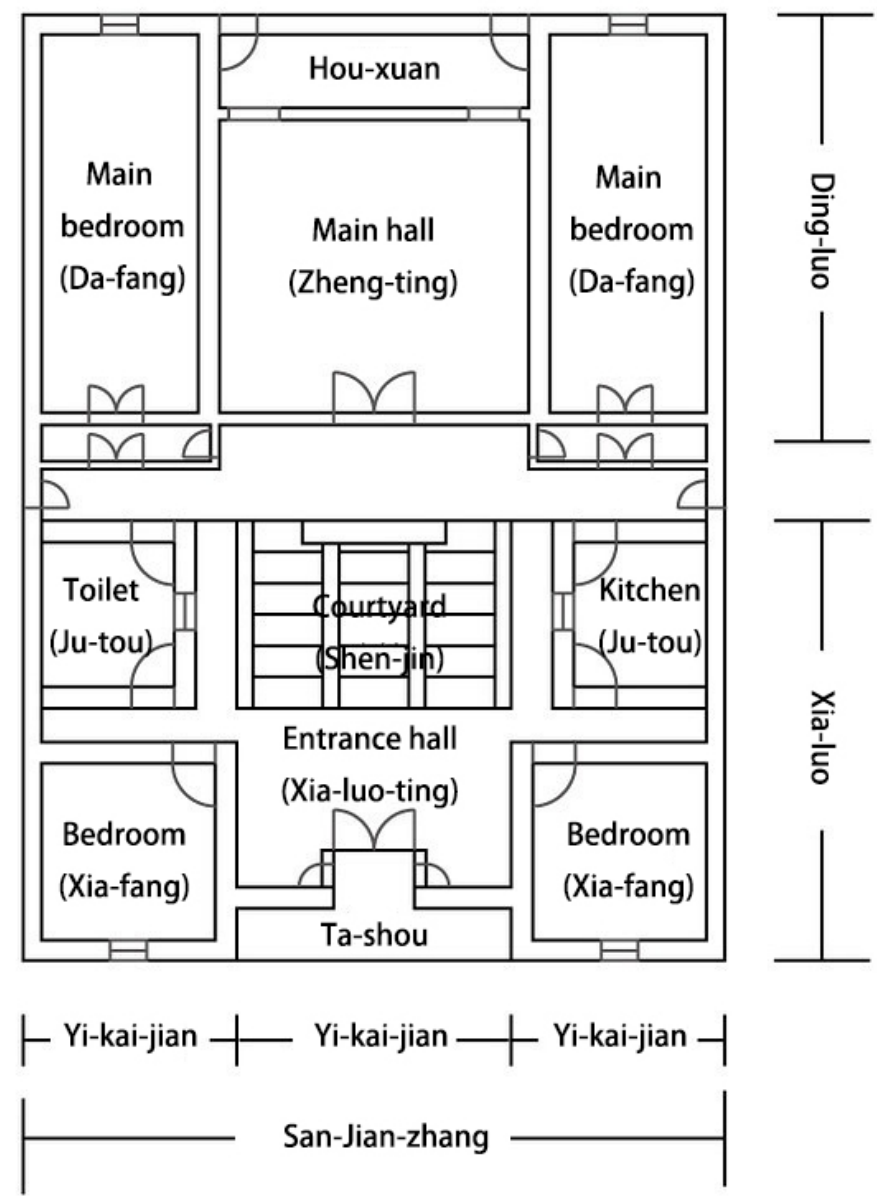

( Figure 1, the plan of 'San-jian-zhang-liang-luo-da-cuo' )

In the typhoon area, rational arrangement of various elements can achieve a good shelter effect. Based on the analysis of the dwellings in southern Fujian with the standard of 'San-jian-zhang-linag-luo-da-cuo', on the both sides of the main house, each side has one 'Ju-tou' which is perpendicular to the main house. At the same time, the tall and smooth gable surface minimizes the windage of the sidewall. When the typhoons cross frontally or diagonally, the 
'Ju-tou' has a shelter effort, which greatly reduces the damage of the airflow affects to the main house. In the same way, when the house is larger and there are one 'Hu-cuo' on both sides, the wind resistance performance will be more obvious.

\section{Wind shelter by the slope of roof}

When typhoons arrive in southern Fujian and Taiwan, often accompany with torrential rains. Taking Xiamen area as an example, every time typhoons landed or affected brought heavy rains to Xiamen. In August 2005, affected by No. 10 strong tropical storm 'coral', from August 13th to 15th, during this time, the rainfall of whole city reached about $400 \mathrm{~mm}$ and the maximum rainfall reached $625 \mathrm{~mm}$. Influenced by No. 13 typhoon 'Taili', the rainfall of whole city reached $170 \mathrm{~mm}$ and the maximum rainfall was $251 \mathrm{~mm}$. In 2006, affected by No. 1 typhoon 'Pearl', the rainfall of whole city was about $150 \mathrm{~mm}$ and the maximum rainfall was $246 \mathrm{~mm}$.

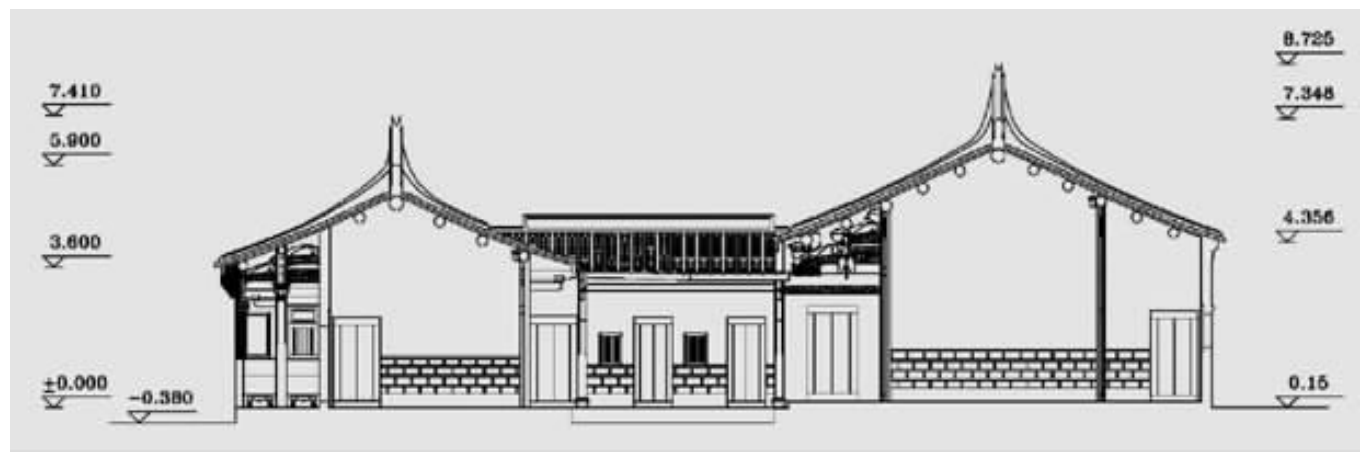

(Fig. 2, the section of a Traditional house in Haicang District, Xiamen)

The roof is one of the weakest parts of traditional houses to against wind. Under heavy storms, the roof is under double pressure and is the most vulnerable part to be damaged. The roof with steep slope is conducive to drainage rapidly, but it is under strong wind pressure during the typhoon that is very unfavorable for wind resistance. The roof with gentle slope has a small force surface during the typhoon, which is more favorable for wind resistance. In the typhoon area, wind resistance performance is the main contradiction, so the traditional houses in southern Fujian all build roof with gentle slope. At the same time, the wind suction even more destructive in the lee-side by the strong winds. They often suck away the tiles, and wind tunnel experiments show that the wind suction is minimum when the slope of double slope roof is $25-30$ degrees. ${ }^{2}$ According to the actual survey of folk houses in Xin'an, Haicang, the slope is usually 24 - 25 degrees. ${ }^{3}$ Therefore, the folk houses in southern Fujian have a scientific slope and can reduce wind suction well (Figure 2).

\section{Wind resistance by structure and construction}

\section{Carpentry work}

The folk houses in southern Fujian adopt the so-called 'Insert-beam construction' carpentry work, which is a mixed structure between the 'post and lintel construction' and 'column and tie construction'.(4) It is common in the Fujian and Zhejiang regions. In this structure, the two ends of the load bearing beams are inserted into the columns, one end or two ends are inserted. It is different from the 'post and lintel construction' which the pressure of the load bearing beams are on the head of columns, also different from the 'column and tie construction' without load bearing columns that the purlins are directly carried by the columns. The form of this structure can not only obtain a bigger space for use, but also increase the adaptability of structural forms (Figure 3). 


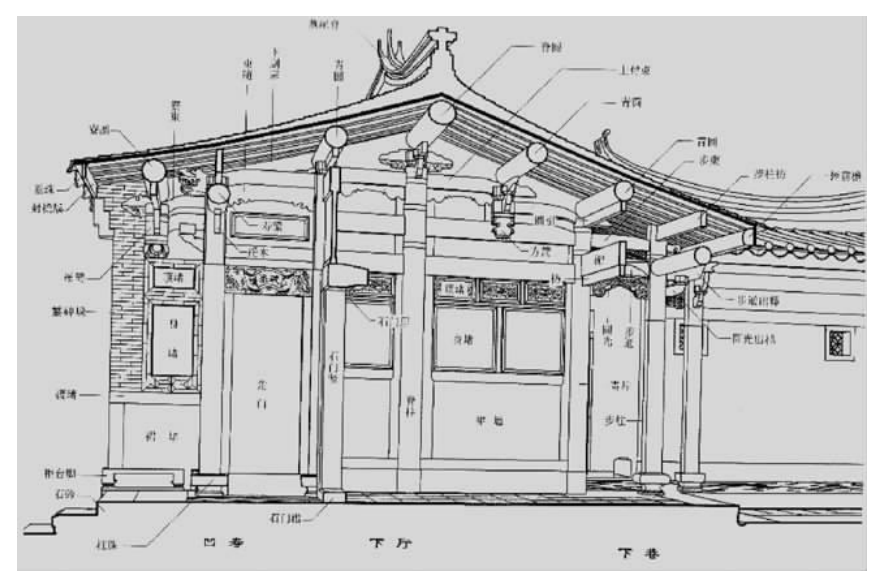

(Fig. 3, Perspective section of the carpentry work of folk houses in southern Fujian source: Cao Chunping, Traditional architecture in southern Fujian)

'Insert-beam construction' combines the characteristics of the 'post and lintel construction' and 'column and tie construction'. It mainly transmits stress through load bearing beams, which is the principle of 'post and lintel construction'. The purlins directly press on the stigma, and the short columns are putted on the beams which are on the bottom. This feature is similar with 'column and tie construction'. From the top to the bottom, the structure is assembled by parts. In addition, at the place where the wood pillars connect with the floor, there is a pillar foundation. The roof structure is integrally combined and it can withstand some deformation while being affected to external forces. After the removal of external forces, it can be restored to its original form.

At the edge of the roof structure, in order to adapt to the hot and rainy climate, the eaves of the traditional buildings in southern Fujian, especially the eaves of somewhere facing to courtyards like 'Xia-ting', 'Ju-tou-ting', 'Ding-ting' and colonnade, the depth of eaves will be longer. The structure of eave is a typical practice in the south of China, so-called 'column and tie'. In the facade of the external walls, in southern Fujian, at the 'Ta-shou' part of the folk houses usually adopt a form of 'one jump bracket set' (in the bracket set, each arch or awning add a layer is called a jump.) at the two sides of eave walls. The depth of the eave is much smaller than that one of the inner courtyard. In some coastal area like Quanzhou, there is even not out of eave or very small eave and it directly intersects with the wall (Figure 4).

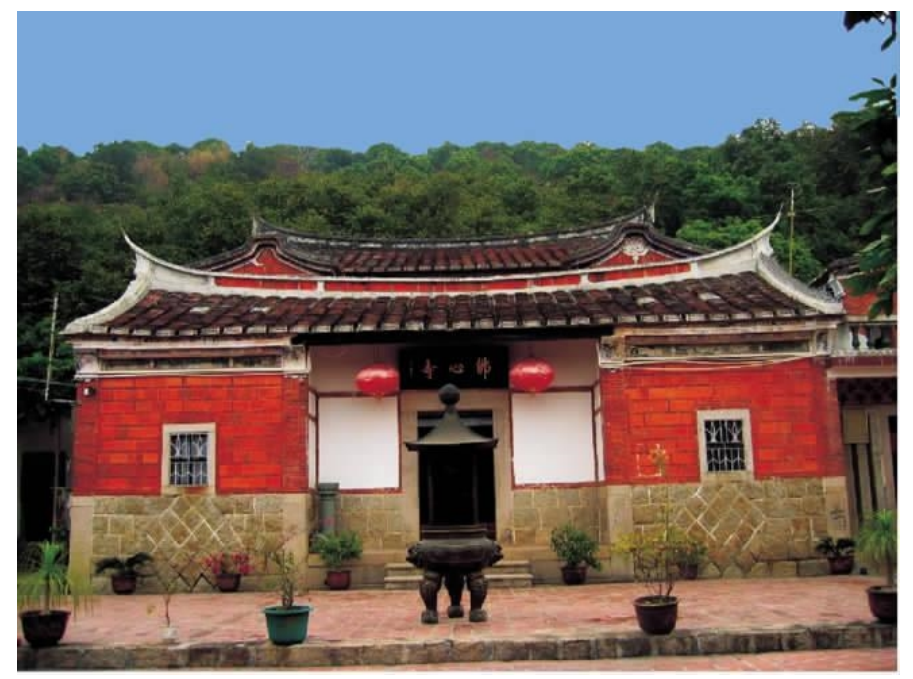

(Fig.4, Frontages of the house in southern Fujian, the sink part of central entrance is known as

'Ta-shou' in the Minnan dialect) 
From the point of view of wind resistance, due to the weakest force point is the eaves, the structure at the eaves to be hinged by the supporting of brackets set, in a certain range of forces, having deformations and displacements but not affecting the integrity of the building, to maximum ensure the eaves will not meet 'hard to hard' and cause permanent damage during the typhoon. On the surface of eave walls, the stress is maximum and is the most vulnerable part to damage in the typhoon. It is an effective method to responding to typhoon adaptability that is using 'eave tiebeam' or not out of eave.

\section{Ridged purlin of roof}

The image of roof with the 'dovetail ridged purlin' or the 'horseback gable roof' is one of the iconic symbols of architecture in southern Fujian. (5) The 'dovetail ridged purlin' and the 'horseback gable roof' are two practices of roof. Both ends of the roof adopt an upward-warping way and its warping ends divide into two parts, shaped like dovetail, so-called 'dovetail ridged purlin'. In addition, the rest of the architecture in southern Fujian, due to the appearance of gable roof are shaped like horseback bows up, commonly known as 'horseback gable roof wall'.

However, what is often neglected is that it also plays an important role in wind resistance. For the entire roof, the intersection of the double slopes is one of the weakest parts. Regardless of whether they use the 'dovetail ridged purlin' or the 'horseback gable roof ' construction, the practices of roof all use sticky 'oyster shell ash' as the adhesive material, which is abundant in the south coast of Fujian. The tiles are stacked and bitten together, the outside is coated with a thick layer of 'oyster shell ash' as the protective layer. This approach has a double stability in the structure and material, superior performance in the long time and well protected the weak part of the roof junction.

\section{Gable roof}

The gables roof of the coastal houses in the southern Fujian are basically 'flush gable roof' and called 'Bao-gui-qi' ${ }^{\circledR}$ (Figure 5). The vertical ridged purlin is called the "Gui-dai". The gable is used to seal the roof with a brick wall, the so-called 'Bao-gui'. In this practice, the vertical ridged purlin of 'flush gable roof' are just on the gable and a few bricks are built from the surface of gable to wrap the vertical ridged purlin. If the eaves at front and back are also sealed with bricks, it is called the 'Huo-ku-qi'. The practice of 'Bao-gui-qi' and 'Huo-ku-qi' hide the part of the junction that between the eaves and the gables, maximum avoid the catastrophic damage caused by the eaves.

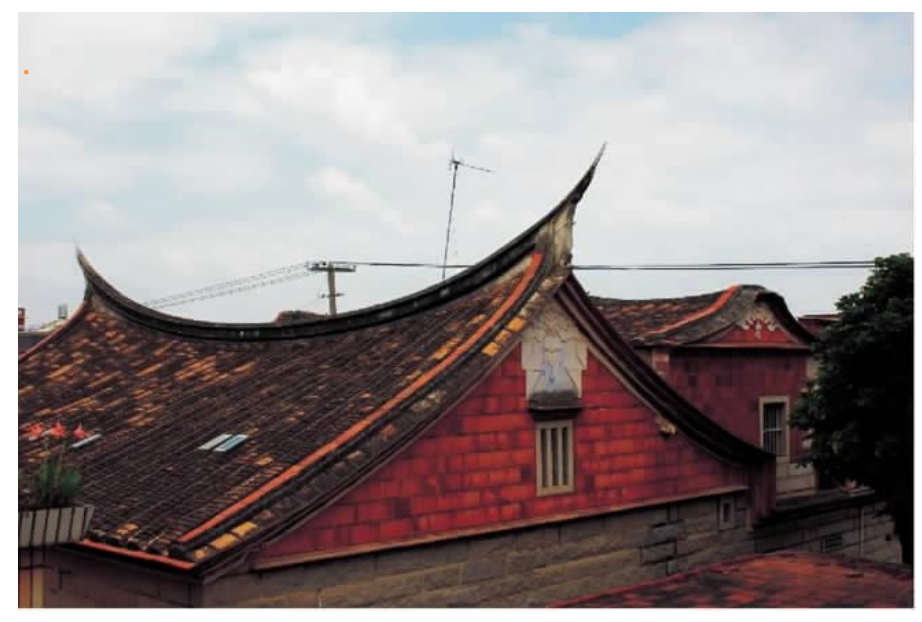

( Fig.5, 'dovetail ridged purlin’ and 'flush gable roof' the so-called 'Bao-gui-qi' )

\section{The Implications for Today's Architectural Design}

In the past, the researches on folk houses in southern Fujian mostly concentrate on the appearance of 'metaphysics' as their layout, form and decoration and neglect the technical aspects behind their appearance. In fact, the natural environment is an extremely important factor for the reason why any 
folk house is different from other house systems. For a long time, the adaptive methods for specific climate finally form a specific architectural layout, form, and construction. On this base, the architectural culture was formed. At the same time, the method of respecting nature is also a feedback to 'passive' and 'low-tech' on specific natural conditions, but it can gradually improve after a period of time and it will produce very good results finally. When facing the strong force by typhoons, traditional folk houses either by avoiding them or adopting allowable distortion to a certain extent, or adopting partial reinforcement measures to maintain the maximum possible self-protection before this powerful natural force. This kind of humility attitude towards nature and flexibility construction methods in responding to nature have many beneficial implications for today's modern architectural design, especially for regional architectural design.

\section{References}

[1] Feng Changgen: The Research of Architectural Climate Analysis and Design Strategy[C], Xi'an: Xi'an University of Architecture and Technology Publishing, (2008)

[2] Lin Dezhi: Adjustable Climate Space of Traditional Houses in Southern Fujian [J], Xiamen: Journal of Xiamen University of Technology (2010), (9): p.82-83

[3] Li Quanshui: The Ecological Research and Design in Residential Buildings, Wuhan: Huazhong University of Science and Technology (2011)

[4] Wang Zhaohui: From Natural Ventilation to Diversified Ecological Construction System in Southern Fujian,[J], Xiamen: Journal of Huaqiao University (2011), (37): p.138-141

[5] Sheng Yunxia: Hot and Humid Climate and Traditional Architecture in Southern Fujian , Xiamen: Xiamen University Publishing (2010)

\section{Note:}

(1) Chen Xiaohui, The Causes and Countermeasures of Typhoon Disaster in Xiamen, China Flood Control and Drought Relief (2008), (6)

(2) Wang Haisong, The Construction Technology Analysis of Traditional Houses in Southeast of Zhejiang under the Influence of Typhoon, New Building (2012), (1)

(3) From the students of Grade 1995, Department of Architecture, Xiamen University, Surveying and Mapping of Traditional Houses in Southern Fujian, Zhongshan Village, Haicang District, Xiamen

(4) Cao Chunping, Traditional Architecture in Southern Fujian, Xiamen University Press, ISBN 7 $2533-8 /$ TU105

(5) Huang Zhuangwei, The Research on Roof Styling Techniques of Modern Regional Architecture in Southern Fujian and Taiwan, Shanxi Architecture (2007), (6)

(6) The language in southern Fujian, which means 'the building method by wrapping the vertical ridged purlin of house', 'qi' means 'the method of building construction' 